\title{
BOOTSTRAP TESTING OF TRADING STRATEGIES IN EMERGING BALKAN STOCK MARKETS
}

\author{
Boris Radovanov, Aleksandra Marcikić
}

\section{Introduction}

Technical analysis is an approach to predicting future prices based on detecting regularity patterns in prices, volume and other market indicators. It ordinarily proceeds by noting market activity in some graphical form and then deducing possible future trends from the observed historical data. This paper stands on the postulate that stock prices manifest various regularities; once these regularities are identified, technical analysts and/or market participants should be consulted about what is likely to happen next. This scenario allows the participants to run a profitable trading strategy and to reject the weak-form market efficiency hypothesis. They identify trends at the early stage and maintain their positions until they notice indications of price movement reversal. The absence of weak-form efficiency, in which information set involve only historical market data, does not necessarily translate into profitable information due to trading costs. Park and Irwin (2007) review international evidence on the profitability of technical analysis and indicate that previous studies are not capable to provide convincing arguments supporting the benefits of technical trading strategies. In addition, most of implemented studies, similar to Fifield et al. (2005), have demonstrated that better trading performances are more possibly to appear in emerging stock markets. This fact is the basic motive to handle such a research. Hence, a technical analysis in stock markets of the Balkan States analogously to other conducted in emerging markets has to be performed.

Most lately, the attention of technical trading analysis has shifted to emerging stock markets which collectively bring a significant alternative source of opportunities to international investors (McKenzie, 2007). On the other hand, investment attractiveness and predictive power seem to disappear in the course of time. Thus, it is of constant interest to examine whether the allurement of technical trading strategies keeps on hold for the most recent sample periods.

According to Brock et al. (1992), stock prices are probably the most studied financial series and most susceptible to data snooping. Therefore, the possibility of various spurious patterns uncovered by technical analysis cannot be dismissed. Although a complete revealed remedy for data snooping biases does not exist, we try to reduce this issue by presenting results from all technical trading rule variants and underline the robustness of results among used bootstrap data generating processes. The introduction of the bootstrap, as a main part of resampling processes, enables testing of diverse null hypothesis for which analytical approaches would be impracticable. The use of resampling methods also offers a possible solution to adjust for the biases caused by data snooping.

The basic hypothesis of this paper is that there is no weak-form efficiency in observed stock markets of neighboring countries, such as proven in the Croatian stock market (Festic et al., 2012). As a matter of fact, earlier research processes in stock markets of neighboring countries have been directed to the stock price movement effects and the risk of such investments, as an example Žiković (2008) or Žiković and Aktan (2009), while so far the researchers ignored the significance of trading rule predictive power. Consequently, the aim of this paper is to examine the profitability and predictive ability of technical trading rules in six stock markets of the states of the Balkan States. Furthermore, the paper is providing resume evidence on the predictive power of four general classes of technical trading rules: moving average, filter, trading range breakout and channel breakout rule. These rules have 
proven to be most popular in the literature and their application will enable immediate comparisons to previous research. In addition, the study provides an analysis about relationships among selected stock markets considering the hypothesis that financial crisis may result in stronger international linkages of stock markets due to more or less simultaneous "contagion" effects (Kizys \& Pierdzioch, 2011).

The paper encompasses six related sections. After the introduction, the first section of research provides the literature review of technical trading rules applied in financial time series. The second section explains theoretical background of technical analysis and indicates the basic types of technical trading rules. The third section outlines the methodology applied in this paper to test predictive ability of technical trading rules. The fourth section describes the observed stock market indices data and analyses the empirical results of trading rules tests. Finally, this paper ends by some recommendations, as well as concluding remarks.

\section{Literature Review}

Brock et al. (1992) tested two of the simplest and most popular technical trading rules by utilizing the Dow Jones index over the period 1897-1985. Their results provide strong encouragement for further development of trading strategies. In the following, the focus of the paper is on the methodology similar to that of Brock et al. (1992), although Sullivan et al. (1999) demonstrated that their forecasting performance has disappeared over recent years due to data snooping problem. On the other side, Bessembinder and Chan (1995) conclude that two simple technical trading rules are successful in predicting stock price movements in Japan, Hong Kong, South Korea, Malaysia, Thailand and Taiwan. Gencay (1998), Ratner and Leal (1999) also support the predictive power of technical trading rules. Kwon and Kish (2002), employing three popular technical trading rules to NYSE index over the period 1962-1996, deduce that the trading rules have the potential to capture profit opportunities over various trading strategies comparing to buy-and-hold policy. However, Ready (2002) emphasize that evident success of applied technical trading rules is spurious result of data snooping and not essentially persist in the future, while Parisi and Vasquez
(2000) and Gunasakarage and Power (2001) found support for the profitability of technical trading rules in several South American and emerging South Asian markets, respectively. Using Singapore Exchange market data, Wong et al. (2003) found that market members tend to achieve sustainable profits by applying technical analysis.

Ben-Zion et al. (2003) compared Tel-Aviv Stock Exchange Index to S\&P 500 Index with implication that market efficiency is higher in developed financial markets then in emerging financial markets. Chang et al. (2004) also found that technical trading rules are profitable on some emerging stock markets. Similarly, McKenzie (2007) tested three technical trading rules for seventeen emerging markets and indicated that some of the trading rules appear to earn significant returns but the forecast accuracy decreases for more recent sample periods.

Most recent evidence on testing technical trading rules in European stock markets presents following results. Metghalchi et al. (2007) showed that moving average rules for the Austrian Stock market have predictive power and can notice price patterns for profitable trading. Metghalchi et al. (2008) applied various trading rules in the Swedish stock market and referred that several moving average strategies outperform buy-and-hold strategy even considering transaction costs and data snooping. Lonnbark and Soultanaeva (2009) presented the results of applying technical trading rules in three stock markets of the Baltic region. They discerned importance of the choice of a methodology for testing the profitability of technical trading rules. Also, Papathanasiou and Samitas (2010), applying Brock et al. (1992) methodology, confirmed in general that used technical strategies win the market, concerning buy-and-hold strategy.

Other recent studies continue to provide a confirmation of the technical trading rule predictive ability but also a few critiques and potential drawbacks. McKanzie (2007) claims that market inefficiency could be a constant feature of emerging financial markets. Similarly, Marshall et al. (2009) consider technical trading rules more profitable for smaller, less liquid stocks. Lento (2010) employed some combined technical trading rules and found that certain combination are profitable even when individual trading rules alone are not. Garza-Gomez and 
Metghalchi (2011) found the Mexican stock market inefficient in years before modernization and futures market introduction, and gradually disappearing of market inefficiency in years after. Moreover, Mitra (2011) investigated moving average trading rules for the Indian stock market and observed that profitable opportunities from technical analysis holds as a puzzle in the stock market. Pauwels et al. (2012) made a comprehensive investigation on 34 emerging stock markets and noticed the inefficiency only in four after an adjustment for transaction costs and data snooping bias. Also, the same group of authors provided evidence that during the recent economic crisis number of inefficient markets are increasing comparing to other observed periods.

Majority of the previously mentioned studies point at the strong possibility to reject the weak-form efficiency hypothesis in case of emerging financial markets. Even after all these facts and with the lack of possible application of the analogous results, the potential profit opportunities are not fully exploited by the stock market analysts in the Balkan States. Often confronting results in previous work pinpoint the importance of separate studying of technical trading rules applicability in the stock markets in the defined region.

\section{Technical Trading Rules}

Technical trading rules or their variants, technical trading strategies, are algorithms that take inputs regarding to stock market, and outputs an investment decision, whether to buy or sell a stock for a given time interval. They have been widespread used tools by traders in financial markets for many decades and their performance has been a topic of extensive research. According to Charoenwong (2012), using daily data permits for more variation in the stock price. Hence, if there is more volatility in the data, there are more potential opportunities to buy and sell stocks. Though the stock market may have indicated a stabile long term price movement pattern, in the short term the price behavior is very noisy. Thus, active trading strategies should be more profitable in the short term with more variation then the long term.

\subsection{Types of Technical Trading Rules}

According to Coe and Laosethakul (2010), every trading strategy is different regarding possible application and predictive power.
Therefore, technical trading rules have to be tested separately and then compared. Similarly to Sullivan et al. (1999) and Qi and Wu (2006), this paper provides a comprehensive coverage of applied technical trading rules in order to obtain significant estimate of data snooping biases. Four popular types of trading rules are considered in this study: moving average, filter, trading range breakout and channel breakout rules. In each case, we assume that the technical analyst and/or market participant initially does not hold any stock position, but he does have starting wealth to be used in the stock trading with a high probability of expected returns growth.

1) The first rule is based on moving averages which are series of simple partial averages of prices $P$ over the previous $n$ trading days, including the current day. They represent a measure of stock price momentum. Therefore, the moving average at time $t$ for $n$ trading days is computed as follows:

$$
M A_{t}^{n}=\frac{1}{n} \sum_{t=1}^{n} P_{t}
$$

Thus, the original time series of stock prices conducts two new series of partial moving averages, one for short term and another for long term. Considering the moving average rule, when the short moving average of stock prices is above the long moving average, the traders initiate buy or hold decision relying on believe that the short term price growth surpass the long term price growth in expected time period. Oppositely, when the short moving average is below the long moving average or when they are equal, the traders make a sell or stayout decision.

A typical number of trading days in short and long term moving averages depends on research assumptions. Hence, Brock et al. (1992) are used 1 and 5 days interval for the short moving average, and from 50 to 200 trading days for the long moving averages, while Charoenwong (2012) considered that the short moving averages can range from 5 to 15 days and the long moving average from 50 to 90 days. This paper implements 1 and 5 days interval for the short, and 100, 150 and 200 trading days for the long moving average.

2) According to Pauwels et al. (2012), filter rules try to avoid spurious trading signals based on short term prices changes. Therefore, 
these trading strategies filter out small price movements and only generate trading signals in the case of larger price changes. However, filter strategies are a set of straightforward rules initiated by the price movements that decide whether to sell or buy stock after a certain percentage of price growth or downfall. To reduce a number of trading signals, we apply the range from $1 \%$ to $10 \%$.

3) Trading range breakout rule generates buying signals when the stock prices exceed the resistance level or the maximum price over the previous $n$ trading days by defined percent. Moreover, when the stock price goes below minimum price over the previous $n$ days by certain percent, the traders decide to sell the stocks. A great number of trading analysts believe that investors are willing to sell at the peak. However, these selling signals will cause resistance to a price rise above the previous peak. Such a breakout is considered to be a buy signal.

In order to implement trading range breakout strategies, we follow the rules consistent with the moving average strategy and set by Brock et al. (1992). The resistance level is determined based on the past 50,100, 150 and 200 trading days.

4) Under the channel breakout rule, the traders buy stock when the closing price goes above the channel and sell it when the closing price goes bellow the channel. A channel is defined as a price span within $\mathrm{x}$ percent of stock price movements over the previous $\mathrm{n}$ trading days. Similar to the trading range breakout rule, this paper use a price span between $1 \%$ and $10 \%$.

\section{Methodology}

\subsection{Bootstrap}

The bootstrap, originally introduced by Efron (1979), appeared as a procedure to measure the accuracy of an estimator. Many researchers have decided to use the bootstrap methodology in case of complex statistical problems. Bootstrap methods are more flexible then classical statistical methods which could be analytically intractable or unusable because of a lack of the appropriate assumptions being satisfied. Those methods are related to Monte Carlo simulation, but with one fundamental difference. Data generating process in Monte Carlo simulation is completely artificial, while bootstrap process obtains a description of the properties of estimators by applying the sample data themselves and involves sampling repeatedly with replacement from the actual data. Thereby, two distinctive advantages of bootstrap procedure over analytical results of traditional statistical methods appear. First, bootstrap method enables the researcher to conduct the inference without considering strong distributional assumptions. The bootstrap includes empirically estimated sampling distribution by looking only at the variations of the statistics within sample. Consequently, bootstrap procedure treats the original sample as a population from which bootstrap samples can be drawn. Second advantage emphasizes bootstrap process as more robust then classical statistical methods. The robustness enables an effective usage of bootstrap methods with relatively small samples and preserves the estimator stability during the periods of unexpected volatility shifts.

Initial bootstrap procedure begins with a set of $n$ independent and identically distributed observations with distribution function $F$ and an unknown parameter as a function of $F$. The bootstrap just described is the simplest version and it is only valid in the case of i.i.d. observations. Therefore, if one applied the i.i.d. bootstrap procedure immediately to dependent observations, the resampled data will not preserve the properties of the original data set. That experience provides inconsistent statistical inferences. With inclusion of dynamic correlation and conditional heteroscedasticity, Ruiz and Pascual (2002) offered a classification of two bootstrap groups (parametric and nonparametric bootstrap) developed for time series data. The parametric methods are based on assuming a specific regression model for the data. If the serial dependence of the data is misspecified by the selected model, the parametric bootstrap could be inconsistent. Consequently, alternative approaches that do not require fitting a parametric model have been developed to deal with time series data. We choose one bootstrap procedure from each mentioned group. However, this paper subsumes two widely used bootstrap methods in financial time series, the residual based bootstrap and the moving block bootstrap method.

\section{Residual Bootstrap}

The parametric bootstrap method is based on assumption that there is always a specific 
regression model suitable enough for time series data. There are two open questions due to the residual based resampled efficiency. First, considering the distribution approximation of population made by the parametric model, it is inevitable to pay attention to model specification. Second, the residual series made by bootstrap procedure could be various thanks to the model estimation method or choice of residual scheme. Ruiz and Pascual (2002) indicated a few types of residual from the same parametric model and noticed different predictive power of residuals in respect to purpose of application. In order to compare the results with mentioned study, this paper uses the $A R(1)-G A R C H(1,1)$ model to estimate stock price returns and generate series of residuals as foundation for bootstrap procedure.

$$
\begin{aligned}
& Y_{t}=\mu+\varphi_{1} \cdot Y_{t-1}+\varepsilon_{t} \\
& \sigma_{t}^{2}=\alpha_{0}+\alpha_{1} \cdot \varepsilon_{t-1}^{2}+\beta \cdot \sigma_{t-1}^{2}
\end{aligned}
$$

where $Y_{t}$ is stock price or stock price return in time $t, \varepsilon_{t}$ is residual in time $t$, and $\sigma_{t}^{2}$ conditional variance in time $t$. Other indices represent the estimation parameters.

The formulation (2) represents conditional mean equation in the $\operatorname{GARCH}(1,1)$ model, while expression (3) shows conditional variance equation of the same model. The parametric bootstrap procedure rely on assumption that the basic time series process follows the final stationary autoregressive model form, as presented in (2). Hence, after defining the form of the estimation model, the residual bootstrap method contains following six iterations:

1. Estimate mentioned autoregressive model on the actual data series.

2. Obtain the fitted values of dependent variable and calculate the series of residuals $\hat{\varepsilon}_{t}=Y_{t}-\left(\hat{\mu}+\hat{\varphi}_{1} \cdot Y_{t-1}\right)=Y_{t}-\hat{Y}_{t}$.

3. Take the sample of size $n$ with replacement from original series of residuals and generate the series of bootstrapped residuals $\varepsilon_{t}^{*}$.

4. Generate a bootstrap dependent variable by adding the fitted values to the series of bootstrapped residuals $Y_{t}^{*}=\left(\hat{\mu}+\hat{\varphi}_{1} \cdot Y_{t-1}\right)+\varepsilon_{t}^{*}$.

5. Estimate the bootstrap parameters of $\operatorname{AR}(1)$ model $Y_{t}^{*}=\mu^{*}+\varphi_{1}^{*} \cdot Y_{t-1}^{*}+\varepsilon_{t}^{*}$.

6. Go back to the step 3 and repeat a total of $B$ times.
Nevertheless, the parametric model has to present an appropriate approximation of true model. Thus the utility value of the residual bootstrap method predominantly depends on adequate model selection procedure.

\section{Moving Block Bootstrap}

Kunsch (1989) and Liu and Singh (1992) proposed separately the moving block bootstrap method that divides the original data set into the overlapping blocks series of fixed length and resample with replacement from these blocks. The moving block bootstrap retains the original structure of financial time series by performing the resample process within defined blocks.

Despite noticed regularities in time series data structure, the accuracy of the moving block bootstrap method primarily relies on optimal block length selection. Therefore, an optimal block length selection depends on sample size, implemented data generating process and chosen statistics of interest. When sample size increases, the block length must pursue the changes in order to secure bootstrap consistency and empirical distribution function. By choosing the optimal block length it is conceivable to minimize the mean squared or absolute error. According to Berkowitz and Killian (2000), a question of block length selection is a matter of compromise. They concluded that as the block length becomes too small, the moving blocks bootstrap desolates the time dependency in the data series and its average accuracy will decrease. Oppositely, as the block length becomes too large, there are few blocks and bootstrap data will gravitate to look alike. Also, bootstrap data generated by moving block with large block size will look similar to independent and identically distributed bootstrap data.

The moving block bootstrap procedure encompasses four indispensable steps in order to assemble an efficient resampling algorithm:

1. Divide time series into overlapping blocks with identical length $I$, where the first block contains a set of $X_{1}, \ldots, X_{l}$ elements, the second one $X_{2}, \ldots, X_{l+1}$ etc.

2. Perform the resampling procedure within defined overlapping blocks and align resampled blocks in one bootstrap sample $X_{1}^{*}, \ldots, X_{n}^{*}$.

3. Estimate the statistics of interest by using the constructed bootstrap sample $T_{n}^{*}=T_{n}\left(X_{1}^{*}, \ldots, X_{n}^{*}\right)$. 
4. Reproduce steps 2 and $3 B$ times to achieve a bootstrap probability distribution of forming the test statistic using indicator function $\hat{G}_{n}\left(t, F_{n}\right)=P^{*}\left(T_{n}^{*} \leq t\right)=\frac{1}{B} \sum_{b=1}^{B} I\left(T_{N, b}^{*} \leq t\right)$.

\subsection{Testing Procedure}

Technical trading rules represent undisputed evidence of the stock price predictive power if expected stock prices depend on available buy/ sell information. To estimate such a relationship it is important to test the difference between expected returns of buy and sell signals or returns of buy/sell signals generated from the technical trading rules and returns of buy-andhold strategy. Obvious choice for this purpose is the t-test of differences between the arithmetic means of two subsamples, presented by the following expressions:

$$
\begin{gathered}
t^{*}=\frac{\bar{R}_{b}-\bar{R}_{s}}{\sqrt{\frac{\sigma_{b}^{2}}{N_{b}}+\frac{\sigma_{s}^{2}}{N_{s}}}} \\
t^{*}=\frac{\bar{R}_{b / s}-\bar{R}}{\sqrt{\frac{\sigma_{b / s}^{2}}{N_{b / s}}+\frac{\sigma^{2}}{N}}}
\end{gathered}
$$

where the $\bar{R}_{b}$ and $\bar{R}_{s}$ are mean returns following the buy and sell signals, $\bar{R}$ is the unconditional mean, $\sigma_{b}^{2}$ and $\sigma_{s}^{2}$ are the variances of returns generated from buy and sell signals, $\sigma^{2}$ is the unconditional variance, $N_{b}$ and $N_{s}$ are the numbers of buy and sell signals, $N$ is the overall number of observed data. The index $\mathrm{b} / \mathrm{s}$ identifies combined buy and sell signals. The results of the t-test will help either accept the null hypothesis (there is no actual difference between mean returns) or reject it (there is an actual difference between mean returns).

The t-test results assume independent, stationary and asymptotically normal distribution. Many times these assumptions do not characterize the financial time series. Therefore, to solve this problem, Brock et al. (1992) and many authors after them used bootstrap methods. Bootstrap experiments help the investigation of estimation biases caused by data snooping. For this reason, White (2000) proposes Reality Check (RC test) procedure for testing the null hypothesis that the model selected in a specification search has no predictive power over the given benchmark model.

At the beginning, the Reality Check extracts the performances of the technical trading rules relative to the benchmark by interpreting the mean return. Actually, the returns of trading rule $k$ at time $t$ are presented as following:

$$
R_{k, t}=R_{t} \cdot I_{k, t-1}
$$

where $R_{t}$ is continuously compound returns $R_{t}=\ln \left(Y_{t} / Y_{t-1}\right)$, and $I_{k, t-1}$ is a dummy variable based on trading signals generated by trading rule $\mathrm{k}$ using available information at time $t$.

The relative performance of trading rule $k$ at time $t$, compared to the buy-and-hold benchmark model or always-long position can be formulated as follows:

$$
f_{k, t}=R_{k, t}-R_{t}
$$

Alternatively, when the benchmark is always neutral position, the relative performance is equal to the returns generated from trading rule $k$, i.e.

$$
f_{k, t}=R_{k, t}
$$

With searching for existence of superior trading rule, the null hypothesis should be tested that the performances of the best trading rule is no better than the benchmark performances, in other words:

$$
H_{0}: \max _{1<k<m}\left(E\left(f_{k}\right)\right) \leq 0
$$

where the expectation is evaluated with a simple arithmetic mean:

$$
\bar{f}_{k}=N^{-1} \sum_{t=1}^{N} f_{k, t}
$$

Rejecting the hypothesis shall guide to the conclusion that the best trading rule achieves performance superior to the benchmark.

White (2000) indicates that the null hypothesis can be tested by applying the bootstrap methodology to the observed values of $f_{k, t}$. The procedure is implemented in the following steps:

1. Resample the realized return series $f_{k, t}$, express the resulting series by $f_{k, t}^{*}$ and repeat this step at least 500 times. 
2. For each replication $i$, compute the simple mean of the bootstrapped returns by

$\bar{f}_{k, i}^{*}=N^{-1} \sum_{t=1}^{N} f_{k, t}^{*}$.

3. Formulate the following statistics:

$$
\begin{aligned}
& T_{N}^{R C}=\max _{1<k<m}\left(N^{1 / 2} \cdot \bar{f}_{k}\right) \\
& T_{N}^{R C, *}=\max _{1<k<m}\left(N^{1 / 2} \cdot\left(\bar{f}_{k, i}^{*}-\bar{f}_{k}\right)\right) .
\end{aligned}
$$

4. Obtain $\mathrm{p}$-value by comparing $T_{N}^{R C}$ to the quintiles of $T_{N}^{R C, *}$. In other words, the $\mathrm{p}$-values are derived by the next indicator function:

$$
p=\left\{\begin{array}{lll}
0 & \text { if } & T_{N}^{R C}<T_{N}^{R C, *} \\
1 & \text { if } & T_{N}^{R C}>T_{N}^{R C, *}
\end{array} .\right.
$$

By utilizing the maximum value over all technical trading rules, the Reality Check procedure covers the effect of data snooping. Nevertheless, Hansen and Lunde (2005) find that this $p$-value can be manipulated when irrelevant models are included. Hence, they propose the Superior Predictive Ability (SPA) test which changes previous procedure on two levels. They use a studentized test statistics and utilize a sample dependent distribution. The SPA test is composed as following:

$$
\begin{aligned}
& T_{N}^{S P A}=\max _{1<k<m}\left(\frac{N^{1 / 2} \cdot \bar{f}_{k}}{\hat{\sigma}_{k}}\right) \\
& T_{N}^{S P A *}=\max _{1<k<m}\left(\frac{N^{1 / 2} \cdot\left(\bar{f}_{k, i}^{*}-\bar{f}_{k}\right)}{\hat{\sigma}_{k}}\right)
\end{aligned}
$$

With an estimator for variance in return:

$$
\hat{\sigma}_{k}^{2}=\operatorname{var}\left(N^{1 / 2} \cdot \bar{f}_{k}\right)
$$

Analogously to formulation (14), the p-values can be derived by comparing $T_{N}^{S P A}$ and $T_{N}^{S P A{ }^{*} \text {. }}$

\section{Empirical Results}

This paper contains evidence on the profitability of a predefined set of technical trading rules in stock market indices of the Balkan States. Also, there is reliable evidence that technical trading rules have some predictive value over the future movements of stock market prices and outperform the always long and the always neutral benchmarks. Additionally, applying of well-known technical trading rules provides an initial test of the weak-form market efficiency hypothesis. If stock markets are efficient, one cannot achieve superior results by using technical trading rules. In other words, all assets in the market will be appropriately priced offering adequate level of expected return to risk (Stavarek \& Heryan, 2012). However, if market inefficiencies are present, profitability opportunities may arise.

\subsection{Data and Summary Statistics}

To be certain in required results and to avoid potential distortions and disagreements caused by different price movement patterns before and after the financial crisis, the paper employs only last five years of price movements when all the observed stock markets denoted some signs of potential recovery. Due to the examination of technical trading rules in the course of time, the paper uses the time period from April 2009 to April 2014 presented by 1,261 daily stock market indices values. Because of the complex supply and demand dynamics of various industries, this study narrows down to stock market indices. The used stock market indices are: The Belgrade Stock Exchange Index (BELEX15), The Zagreb Stock Exchange Index (CROBEX), The Ljubljana Stock Exchange Index (SBITOP), The Sarajevo Stock Exchange Index (SASX-10), The Macedonian Stock Exchange Index (MBI10) and The Montenegro Stock Exchange Index (MONEX20). All mentioned indices are considered as indicators of average stock price movements in six small emerging financial markets which possess very short trading history.

According to Žiković (2008), developing stock market indices form Croatia and stock markets of other states of the former Yugoslavia significantly differ in statistical characteristics from the developed markets. Tab. 1 contains descriptive statistics of daily returns for the entire series of stock market index values of six Balkan States. The results show strongly leptokurtic feature of data series with some signs of skewness, especially in the MONEX20. The volatility is almost at the same level for all six stock market indices. Serial correlations $\rho(i)$, estimated at lag i for each data series, 
Tab. 1: Descriptive statistics

\begin{tabular}{l|c|c|c|c|c|c}
\multicolumn{1}{c|}{ Index } & BELEX15 & CROBEX & \multicolumn{1}{c|}{ SBITOP } & SASX-10 & \multicolumn{1}{c}{ MBI10 } & MONEX20 \\
\hline Mean & 0.00002 & 0.00002 & -0.00014 & -0.00035 & -0.00031 & 0.00011 \\
\hline Max & 0.08250 & 0.08563 & 0.03721 & 0.05938 & 0.07115 & 0.11286 \\
\hline Min & -0.07471 & -0.07020 & -0.06059 & -0.06940 & -0.06647 & -0.07497 \\
\hline Std & 0.01293 & 0.01172 & 0.01028 & 0.01016 & 0.01234 & 0.01319 \\
\hline Skewness & 0.41146 & 0.25187 & -0.17799 & 0.22389 & 0.22814 & 1.38286 \\
\hline Kurtosis & 8.97597 & 11.20972 & 5.33171 & 8.58919 & 8.10252 & 16.02261 \\
\hline$\rho(1)$ & 0.26062 & 0.11022 & 0.07203 & 0.14631 & 0.18202 & 0.19221 \\
\hline$\rho(2)$ & 0.11310 & -0.01619 & -0.00721 & 0.02203 & -0.03104 & 0.07706 \\
\hline$\rho(3)$ & 0.04103 & 0.07003 & -0.00920 & 0.01717 & -0.02236 & 0.02218 \\
\hline$\rho(4)$ & 0.10424 & 0.02529 & -0.02537 & -0.00423 & 0.02314 & 0.01354 \\
\hline$\rho(5)$ & 0.04600 & -0.00331 & 0.05009 & 0.01784 & 0.08533 & -0.02101 \\
\hline
\end{tabular}

Source: own

Notes: The skewness of the normal distribution is zero. If this statistic is negative, then the data are spread out more to the left of the mean. If the skewness is positive, the data are spread out more to the right. The kurtosis of the normal distribution is 3. A distribution with fat tails has kurtosis greater then 3 , while a distribution with lower peak has this statistic less than 3. $\rho(i)$ is the estimated autocorrelation at leg i for each series.

are generally small with the exception of a few relatively large values at the first lag. The data provides large enough samples to generate robust trading strategies that accomplish long term surplus profits as opposed to short term profits that do not automatically perform any possible trends in the stock prices.

\subsection{Results of Applying Technical Trading Rules}

Resume of research process considers the implementation of technical trading rule strategies to the series of historical return data. This paper includes 18 different trading strategies from 4 explained technical trading rules. The strategies differ by the length of averages or percentage spans denoted in the parentheses. Tab. 2 presents the results of applying different technical trading rules and enable further comparison of trading rules in the light of comprehending buy and sell signal origins.

Tab. 2 includes 18 technical trading strategies with adhered statistics in previously mentioned data sample. First column of these tables brings short description of applied trading strategy. In such a way, the moving average rule is expressed in parentheses with short and long moving averages respectively.
The range breakout rule is briefly explained by the length of previous time intervals for deriving local minimum and maximum. Finally, the filter and channel breakout rules contain percentage deviation for daily observed returns defined in advance. Next two columns N(buy) and N(sell) record the number of buy and sell signals reported during the sample interval. $R_{t}$ (buy) and $R_{t}$ (sell) columns indicate the average returns of buy and sell signals respectively. Then, $R_{t}>0$ (buy) and $R_{t}>0$ (sell) are the fraction of buy and sell returns greater than zero. And finally the last column shows the t-statistics of differences between the arithmetic means of buy and sell returns.

First impression about mentioned table is the presence of a significant difference in the number of generated buy and sells signals among all trading strategies. The moving average and filter rule, with no extra percentage needed to generate a trading signal, divide approximately all trading signals into the buy and sell signals. However, the appearance of a trading signal does not represent immediate buy or sell action. A sell signal should be a precaution for investors to stay out of the potential stock investment until another trading signal appears. Otherwise, a buy signal without making any investment activity could be an unquestionable evidence of retaining given 


\section{Tab. 2: Results for various trading strategies using BELEX15}

\begin{tabular}{l|r|r|r|r|r|r|r|r}
\multicolumn{1}{c|}{ Strategy } & $\mathbf{N}$ (buy) & N(sell) & Rt(buy) & Rt(sell) & Rt>0(buy) & Rt<0(sell) & t-test & p-value \\
\hline $\mathrm{ma}(1,100)$ & 461 & 642 & 0.00101 & -0.00002 & 0.50108 & 0.49221 & 1.99532 & 0.04624 \\
\hline $\mathrm{ma}(1,150)$ & 434 & 573 & 0.00167 & -0.00133 & 0.54608 & 0.44503 & 6.25279 & 0.00000 \\
\hline $\mathrm{ma}(1,200)$ & 407 & 553 & 0.00049 & -0.00105 & 0.50614 & 0.46112 & 3.41630 & 0.00066 \\
\hline $\mathrm{ma}(5,100)$ & 545 & 510 & 0.00121 & -0.00128 & 0.54312 & 0.43333 & 5.14846 & 0.00000 \\
\hline $\mathrm{ma}(5,150)$ & 428 & 579 & 0.00089 & -0.00072 & 0.51636 & 0.46805 & 3.33994 & 0.00086 \\
\hline $\mathrm{ma}(5,200)$ & 408 & 552 & -0.00001 & -0.00068 & 0.48775 & 0.47464 & 1.47872 & 0.13949 \\
\hline filter0.001 & 556 & 591 & 0.00628 & -0.00587 & 0.75180 & 0.23350 & 24.70290 & 0.00000 \\
\hline filter0.002 & 502 & 645 & 0.00691 & -0.00535 & 0.76892 & 0.26357 & 24.70110 & 0.00000 \\
\hline filter0.005 & 360 & 787 & 0.00880 & -0.00400 & 0.81944 & 0.33164 & 24.36530 & 0.00000 \\
\hline filter0.01 & 209 & 938 & 0.01173 & -0.00259 & 0.84211 & 0.40512 & 24.05710 & 0.00000 \\
\hline $\operatorname{trb}(50)$ & 132 & 123 & 0.01308 & -0.01003 & 1.00000 & 0.00000 & 36.70280 & 0.00000 \\
\hline $\operatorname{trb}(100)$ & 96 & 69 & 0.01199 & -0.01209 & 1.00000 & 0.00000 & 36.35500 & 0.00000 \\
\hline $\operatorname{trb}(150)$ & 64 & 83 & 0.01324 & -0.00737 & 1.00000 & 0.00000 & 32.57360 & 0.00000 \\
\hline $\operatorname{trb}(200)$ & 26 & 132 & 0.00904 & -0.00417 & 1.00000 & 0.00000 & 30.01350 & 0.00000 \\
\hline channel0.001 & 494 & 449 & 0.00308 & -0.00239 & 0.61336 & 0.36971 & 10.24830 & 0.00000 \\
\hline channel0.002 & 420 & 403 & 0.00369 & -0.00250 & 0.62619 & 0.37221 & 11.02500 & 0.00000 \\
\hline channel0.005 & 229 & 264 & 0.00511 & -0.00308 & 0.64192 & 0.34848 & 12.35130 & 0.00000 \\
\hline channel0.01 & 110 & 106 & 0.00784 & -0.00467 & 0.68182 & 0.30189 & 15.00220 & 0.00000 \\
\hline
\end{tabular}

Source: own

Notes: The moving average rule is identified as ma(short, long average return). The Filter rule is presented as filter(percentage of price movements). The trade range breakout rule enters in parentheses the number of previous days for measuring resistance level. The Channel breakout rule is defined as channel(price span within determined percentage). Also, because of the lack of space, the paper show only the trading results in case of BELEX15.

stocks in the investment portfolio. Usually, the first trading signal in a series of buy or sell signalsis assumed to be of most interest due to the fact of existing stock price autocorrelation. According to basic mechanism of generating trading signals, the trade range breakout rule compared to other two mentioned trading rules infrequently induces buy/sell signals. Such a mechanism gathers more credibility of the investor, but does not encourage enough the growth of activity at the stock market. Similar to previous, the channel breakout rule generates a number of trading signals directly opposite to defined upper and lower band of the channel.

Presented strategies achieved significantly different results observing a whole sample of 5 years of daily stock price returns. The majority of 18 trading strategies obtains a positive average one-day return on buy-signals and a negative average one-day return on sell-signals and compared with unconditional one-day average in Tab. 1 it rejects the null hypothesis that the returns equal the unconditional returns at the 5 percentage significance level using a twotailed test. These t-test results are presented in Tab. 3.

Back to the description of Tab. 2, $R_{t}$ (buy) column mainly exceeds 50 percent, while $R_{t}($ sell) column stays below 50 percent. The results of these two indicators give a confirmation that applied technical trading rules produce useful trading signals. As mentioned by Brock et al. (1992), the negative returns for sell signals are particularly meaningful. These returns cannot be explained by different seasonalities since they are based on about 30 percent of all trading days in 18 trading strategies. Hence, the returns made from trading rules are likely to be predictable. The return predictability can reflect the rejection of market efficiency 
Tab. 3: Testing of differences between trading strategy mean and unconditional mean

\begin{tabular}{l|c|c|c|c|c|c}
\multicolumn{1}{c|}{ Strategy } & BELEX15 & CROBEX & SBITOP & SASX-10 & MBI10 & MONEX20 \\
\hline $\mathrm{ma}(1,100)$ & 1.54478 & 0.03063 & 4.40231 & 3.01900 & 0.26389 & 3.39481 \\
\hline $\mathrm{ma}(1,150)$ & 4.50517 & 2.51854 & 4.07085 & 3.10771 & 2.60893 & 2.51326 \\
\hline $\mathrm{ma}(1,200)$ & 2.31750 & 1.94371 & 2.84205 & 2.89108 & 2.15028 & 1.93926 \\
\hline $\mathrm{ma}(5,100)$ & 3.73080 & 1.30446 & 1.87367 & 1.58724 & 1.12994 & 1.33393 \\
\hline $\mathrm{ma}(5,150)$ & 2.42005 & 1.43947 & 0.97222 & 1.29688 & 1.32101 & 1.29103 \\
\hline $\mathrm{ma}(5,200)$ & 1.00631 & 0.17368 & 1.27085 & 0.48426 & 0.04667 & -0.13064 \\
\hline filter 0.001 & 18.22250 & 15.01000 & 15.63640 & 13.56160 & 15.43200 & 16.26290 \\
\hline filter 0.002 & 18.38590 & 15.16530 & 15.77940 & 13.93950 & 15.66910 & 16.31640 \\
\hline filter 0.005 & 19.19080 & 17.13090 & 16.42890 & 15.11150 & 17.17270 & 17.49820 \\
\hline filter 0.01 & 21.47350 & 20.69080 & 17.57320 & 17.31980 & 20.78490 & 20.69280 \\
\hline trb $(50)$ & 34.65520 & 32.14650 & 31.90460 & 27.39590 & 33.12530 & 34.20760 \\
\hline trb $(100)$ & 36.11160 & 33.16110 & 30.79640 & 26.40350 & 33.84010 & 30.39890 \\
\hline trb (150) & 30.90420 & 22.70350 & 27.25230 & 22.62150 & 22.84200 & 27.07870 \\
\hline trb $(200)$ & 19.81940 & 15.55560 & 24.68230 & 18.28380 & 15.43140 & 21.16760 \\
\hline channel 0.001 & 8.19866 & 5.97173 & 6.86922 & 6.74923 & 6.05186 & 7.50347 \\
\hline channel 0.002 & 9.28053 & 7.56726 & 8.32808 & 7.90224 & 7.73319 & 9.17137 \\
\hline channel 0.005 & 12.28170 & 11.16950 & 13.22220 & 10.81360 & 11.68700 & 14.00490 \\
\hline channel 0.01 & 18.76670 & 6.53685 & 28.59270 & 16.61790 & 6.77650 & 20.43590 \\
\hline
\end{tabular}

Source: own

Notes: The results are standard t-ratios testing the difference between buy and sell one-day returns and unconditional one-day mean return.

hypothesis. Although it is difficult to distinguish such an explanation from the equilibrium model expected returns. Also, t-test of difference between returns in buy and sell trading days are performed in Tab. 2. There are only a few trading strategies in all six observed stock market indices which accept the null hypothesis of statistical equivalence between returns on buy and sell signals. Leaving those inefficient trading strategies, for example ma $(1,100)$ for CROBEX and MBI10, ma $(5,150)$ for SBITOP or $\mathrm{ma}(5,200)$ for BELEX15, CROBEX, SASX-10, MBI10 and MONEX20, the paper proposes a set of trading tools with significant predictive power and a high possibility of making profitable investment. This fact once more points out the awareness of applying technical trading rules in emerging stock markets such as the stock markets of the Balkan States. Besides, all six stock markets show similar stock price movement patterns and separate several dominant trading strategies.
Generally, there are more sell signals in observed sample. In overall, SBITOP, SASX-10 and MONEX20 generate sell signals in more than $63 \%$ of all trading signals. In a similar situation are other studied indices which produce about $57 \%$ of sell signals in total sample. This epilogue indicates the signs of moderately to entirely reduced stock market activity and draws attention to the lack of market capitalization. Otherwise, Pauwels et al. (2012) consider it as a support of the efficient market hypothesis. Even though, these rules are still capable to produce positive returns over the entire sample period due to the fact that the profits achieved by winning trades exceed the losses generated by the losing trades.

\subsection{Bootstrap Testing Technical Trading Rules}

Combining the concept of bootstrap and application of technical trading rules in order to evaluate a model specification creates a wide 
spectrum of possible practical usefulness. First noticed by Brock et al. (1992), the mentioned combination provides information about necessary model modification in order to achieve better description of observed stock return time series. Using bootstrap procedure, these authors draw residual series from estimated regression model and then measure profits of technical trading rule for each bootstrapped sample and compare them with profits derived from the original data series. Mills (1997) applies previous methodology on the FT30 index and shows that even though the used technical trading rules surpass profits of defined benchmark in the time interval, their predictive ability significantly decline after the observed period. However, many other authors try to implement this combining procedure, for an example, LeBaron (1999) tests the predictive power of the exchange rate using technical trading rules during the period with and without interfering of the Federal Reserve. Anyway, in all previous studies data snooping has been prevalent due to the lack of practical methods that are suitable of assessing its potential obstacles in variety of situations. Therefore, White (2000) proposes the Reality Check procedure for testing the null hypothesis that the selected model has no predictive power over a given benchmark model. The procedure allows aggressive model searching to be initiated with confidence that one will not confuse results that could have been generated by chance for genuinely good results. Thus, the $\mathrm{RC}$ procedure tests the superiority of selected model over the benchmark after involving data snooping effects. Also, this paper has no attention to disregard the Superior Predictive Ability test created by Hansen and Lunde (2005) established on the disadvantages of previous methodology.

Bootstrap procedure provides a better approximation of a given statistics derived from technical trading rules and makes a decision about how a certain statistical model can explain the results of these rules in appropriate way. Through the bootstrap simulation processes in the investment period of time the mentioned tests will show the level of profit in applying defined technical trading rules and will isolate the superior rule. In order to achieve that, two benchmarks are used to assess the excess return from each studied trading rule: always long and always neutral position. In the always long position, the investors buy and hold certain stocks during the entire forecasting period. In the always neutral position, the investors are not taking any action (buy or sell) and simply

\section{Tab. 4: Relative performance of the best trading rule without transaction costs}

\begin{tabular}{|c|c|c|c|c|c|c|c|c|}
\hline \multirow[b]{2}{*}{ Index } & \multirow{2}{*}{$\begin{array}{c}\text { Bootstrap } \\
\text { method }\end{array}$} & \multirow{2}{*}{$\begin{array}{l}\text { Best } \\
\text { trading } \\
\text { rule }\end{array}$} & \multicolumn{3}{|c|}{ Benchmark: always long } & \multicolumn{3}{|c|}{ Benchmark: always neutral } \\
\hline & & & $\begin{array}{c}\text { Nominal } \\
\mathrm{p} \text {-value }\end{array}$ & $\begin{array}{c}R C \\
p \text {-value }\end{array}$ & $\begin{array}{c}\text { SPA } \\
p \text {-value }\end{array}$ & $\begin{array}{c}\text { Nominal } \\
\text { p-value }\end{array}$ & $\begin{array}{c}R C \\
\text { p-value }\end{array}$ & $\begin{array}{c}\text { SPA } \\
\text { p-value }\end{array}$ \\
\hline \multirow{2}{*}{ BELEX15 } & MBB & filter0.001 & 0.000 & 0.006 & 0.004 & 0.000 & 0.003 & 0.002 \\
\hline & Residual & $\mathrm{ma}(1,150)$ & 0.001 & 0.012 & 0.015 & 0.001 & 0.009 & 0.005 \\
\hline \multirow{2}{*}{ CROBEX } & MBB & filter0.002 & 0.000 & 0.009 & 0.006 & 0.000 & 0.008 & 0.004 \\
\hline & Residual & filter0.002 & 0.002 & 0.015 & 0.011 & 0.001 & 0.013 & 0.009 \\
\hline \multirow{2}{*}{ SBITOP } & MBB & $\operatorname{trb}(50)$ & 0.000 & 0.005 & 0.003 & 0.000 & 0.005 & 0.004 \\
\hline & Residual & filter0.002 & 0.000 & 0.022 & 0.015 & 0.000 & 0.018 & 0.013 \\
\hline \multirow{2}{*}{ SASX-10 } & MBB & filter0.001 & 0.000 & 0.011 & 0.010 & 0.000 & 0.010 & 0.009 \\
\hline & Residual & $\operatorname{trb}(100)$ & 0.002 & 0.026 & 0.023 & 0.000 & 0.021 & 0.022 \\
\hline \multirow{2}{*}{ MBI10 } & MBB & filter0.001 & 0.003 & 0.019 & 0.016 & 0.002 & 0.018 & 0.015 \\
\hline & Residual & filter0.002 & 0.006 & 0.055 & 0.043 & 0.004 & 0.052 & 0.041 \\
\hline \multirow{2}{*}{ MONEX20 } & MBB & $\operatorname{trb}(100)$ & 0.000 & 0.002 & 0.001 & 0.000 & 0.000 & 0.000 \\
\hline & Residual & $\mathrm{ma}(1,100)$ & 0.000 & 0.014 & 0.009 & 0.000 & 0.012 & 0.008 \\
\hline
\end{tabular}


holds previously bought stocks throughout the investment horizon. Tab. 4 presents the relative performance of the best technical trading rule considering two recognized benchmarks.

Tab. 4 presents the performance statistics of the trading models before including transaction costs. The bootstrap tests of mentioned statistics are performed by 1,000 repetitions or bootstrap samples $(B=1,000)$ on three different performance levels. According to Qi and Wu (2006), the nominal p-value is computed by applying the Reality Check procedure to the best technical trading rule only, thereby ignoring the effects of data snooping biases. By interpreting the nominal p-values from Tab. 4, this study confirms that before extracting data snooping biases, the relative performance of technical trading rules is strongly significantly in all observed stock markets. It means that technical trading rules significantly outperform two benchmarks. These results are not disappointing, as they correspond with previous studies on technical trading rules in emerging markets, such as surveys of Parisi and Vasquez (2000), Gunasakarage and Power (2001), Chen et al. (2009) and Pauwels et al. (2012) etc. The Reality Check p-value, on the other hand, is measured by applying the Reality Check procedure to the whole set of technical trading rules and therefore corrects for the biases due to data snooping. This correction for data snooping in RC methodology alters given results. Nevertheless, the null hypothesis that technical trading rule does not possess certain utility comparing to the benchmark can be rejected at the 5 percent level of significance for the case of the MBI10 index. The performance results of other stock market indices at the 5 percent level of significance remain within the previous decision made by the nominal $p$-value. Additionally, the SPA procedure is performed to check once more the performance results after data snooping corrections. Comparing nominal with RC and SPA p-values in Tab. 4, the differences are obvious, but with no statistical significance in the case of the MBI10 index at the 5 percent level. Also, as expected, the performance results indicate some differences between the RC and the SPA procedure. These outcomes are supporting research study of Hansen and Lunde (2006), who conclude that the involvement of one or more poor performing technical trading rules can have significant influence on the Reality Check p-value. When interpreting the performance results of the MBI10 index, the RC p-values are 0.055 and 0.052 for always long and always neutral position, respectively. The conclusion from those results would be that the best technical trading rule is not able to outperform both benchmarks. Nonetheless, when examining the SPA p-values, which show 0.043 and 0.041 , this study confirms that the benchmark is not a best possible trading solution at the 5 percent level of significance. This fact emphasize that the Reality Check procedure sometimes unjustifiable punishes the best performing technical trading rule when a large number of poor performing rules are present. There are also visible differences between two applied bootstrap methods. The moving block bootstrap shows relatively stable results comparing to the residual based bootstrap.

However, maybe it is premature to infer that the best performing technical trading rules presented in Tab. 4 are actually profitable because of the absence of consideration for the transaction cost effects on the technical trading rule performance. These effects can certainly be important when the trading frequencies are high. Even though the percentage of transaction costs per trade can be low, frequent trading can accumulate the small costs per trade into a substantial number. Therefore, Tab. 5 presents the relative performance of technical trading rules after involving a certain percentage of transaction costs per trade. In practice, it is not rational to trade if expected return implied by the trading signal is not higher than the transaction costs per trade. Hence, a larger transaction cost enforce greater penalty on the trading rules that generated more trading signals. After all, the assumption made from this fact is that a rule with less frequent trading has more probability to be selected as the optimal rule. This study considers the transaction cost of $1 \%$ per trade and a market transaction will be assessing only if expected return exceed presumed costs.

Compared to the baseline results in Tab. 4, the results in Tab. 5 indicate that the costs have relatively small effect on the overall performance of the technical trading rules. In many cases, the best performing rule for stock index is identifying to be the same type with or without transaction costs, but with different parameterization, such as the case of BELEX15, SASX-10, MBI10 and MONEX20 
Tab. 5: Relative performance of the best trading rule with transaction costs

\begin{tabular}{l|l|l|l|c|c|c|c|c}
\multirow{2}{*}{ Index } & \multirow{2}{*}{$\begin{array}{c}\text { Bootstrap } \\
\text { method }\end{array}$} & $\begin{array}{c}\text { Best tra- } \\
\text { ding rule }\end{array}$ & $\begin{array}{c}\text { Nominal } \\
\text { p-value }\end{array}$ & $\begin{array}{c}\text { RC } \\
\text { p-value }\end{array}$ & $\begin{array}{c}\text { SPA } \\
\text { p-value }\end{array}$ & $\begin{array}{c}\text { Nominal } \\
\text { p-value }\end{array}$ & $\begin{array}{c}\text { RC } \\
\text { p-value }\end{array}$ & $\begin{array}{c}\text { SPA } \\
\text { p-value }\end{array}$ \\
\hline \multirow{2}{*}{ BELEX15 } & MBB & filter0.002 & 0.000 & 0.011 & 0.009 & 0.000 & 0.008 & 0.006 \\
\cline { 2 - 9 } & Residual & ma(1,150) & 0.003 & 0.031 & 0.024 & 0.002 & 0.026 & 0.020 \\
\hline \multirow{2}{*}{ CROBEX } & MBB & filter0.005 & 0.002 & 0.016 & 0.011 & 0.000 & 0.011 & 0.009 \\
\cline { 2 - 10 } & Residual & trb(150) & 0.004 & 0.027 & 0.023 & 0.002 & 0.024 & 0.018 \\
\hline \multirow{2}{*}{ SBITOP } & MBB & channel0.01 & 0.000 & 0.013 & 0.008 & 0.000 & 0.010 & 0.005 \\
\cline { 2 - 10 } & Residual & filter0.005 & 0.005 & 0.041 & 0.038 & 0.004 & 0.036 & 0.033 \\
\hline \multirow{2}{*}{ SASX-10 } & MBB & filter0.002 & 0.000 & 0.024 & 0.019 & 0.000 & 0.022 & 0.014 \\
\cline { 2 - 10 } & Residual & trb(100) & 0.006 & 0.052 & 0.050 & 0.005 & 0.048 & 0.041 \\
\hline MBI10 & MBB & filter0.002 & 0.006 & 0.035 & 0.033 & 0.004 & 0.031 & 0.025 \\
\cline { 2 - 10 } & Residual & filter0.005 & 0.007 & 0.084 & 0.077 & 0.004 & 0.079 & 0.072 \\
\hline MONEX20 & MBB & trb(100) & 0.000 & 0.015 & 0.014 & 0.000 & 0.010 & 0.015 \\
\cline { 2 - 9 } & Residual & ma(1,150) & 0.002 & 0.032 & 0.030 & 0.000 & 0.031 & 0.024 \\
\hline
\end{tabular}

Source: own

Notes: See notes from Tab. 4.

indices. Also, some trading rules do not persist with involving the transaction costs, for example the case of CROBEX and SBITOP indices. An explanation for such changes in outcomes can be found in the number of produced trading signals per rule. According to Pauwels et al. (2012), this implies that holding periods are very short and transaction costs high. Consequently, the differences in parameterization of trading rules or even change of a trading rule in each case are explained by the need for less trading periods.

At the same time, comparing the results in Tab. 4 and Tab. 5 shows some signs of sensitivity analysis to examine the robustness of results. Data snooping biases from transaction costs are relatively small and cause no harm in the case of BELEX15, CROBEX, SBITOP and MONEX20 indices. Hence, a given performance results are highly robust.

The degree of data snooping biases is found to be more serious in the Reality Check $p$-values then in the nominal $p$-values. When the always long benchmark is applied, the Reality Check p-values are significant at the one percent level for all observed stock indices and at the five percent level for two of six indices. In other words, the Reality Check $\mathrm{p}$-values can be rejected at the ten percent level for the SASX-10 and the MBI10 and at the five percent level for the other involved indices. Slightly smaller results of $p$-value are shown by SPA p-values which reject the hypothesis of better benchmark in the case of the BELEX15 and the SBITOP when using the moving block bootstrap procedure. Using the always neutral position as a benchmark, the study finds in the $\mathrm{RC}$ and the SPA procedures that the hypothesis can be rejected at the ten percent level for the $\mathrm{MBI} 10$ and at the five percent level for the others. These results show better performances using active investment strategy compared to passive one applied in case of six emerging financial markets, confirming the main findings made by Fifield et al. (2005), Metghalchi et al. (2008), Papathanasiou and Samitas (2010) etc. Also, similar to the study of Pauwels et al. (2012), this paper justifies the existence of inefficient markets during and few years after the financial crisis.

\section{Conclusions}

This paper considers the ability of an extensive range of technical trading rules to forecast future stock market movements for a sample of emerging stock markets in the Balkan States. Overall, results of this study contain strong 
support for the technical trading rules we have explored. If technical analysis does not have any predictive power, then the average buy day return is not differ substantially from the average sell day return. Our results indicate that almost all buy-sell differences are positive and t-statistics rejecting the null hypothesis of equality of average buy and sell returns. In other words, presented results generated by the implementation of technical trading rules on the stock market indices reject the weakform market efficiency hypothesis. Further, it is distinctive that applied technical trading rule algorithms in all six stock market indices generate more losing trades then winning trades.

While numerous studies report significant profitability of certain technical trading rules, it is unsure whether their superior performance is due to actual financial information, or is due to a combination of accidental circumstances. The main problem is simultaneous application of numerous technical trading rules to a data set and there is high possibility that some rules may work well by pure chance regardless of their information set. This is the genuine data snooping problem in finance which is treated through this study by the popular Reality Check and Superior Predictive Ability algorithm. However, the evidence from six stock markets of the Balkan States indicates that the data snooping problem is in general rarely serious. Namely, even after including data snooping biases, this study finds that the null hypothesis that trading rules do not outperform the benchmark can be rejected at the $5 \%$ significance level for five separate stock indices. Although the discovery of profitable technical trading rules should be helpful in understanding stock market dynamics, investors must consider transaction costs. Imposing reasonable percent of transaction costs in all six observed stock market indices does not notably affect the basic bootstrap test results.

All stated technical trading rules represent just a fragment of a comprehensive investment portfolio management analysis. For example, Pauwels et al. (2012) described that their analysis of similar type did not show any evidence about that investors are able to detect the best technical rule ex ante. Notice that even if these technical trading rules obtain higher returns, this will not naturally lead to more significant results. Therefore, complete understanding of the stock price movements in observed period requires tools of the fundamental investment analysis, which mainly rely on personal opinion and experience of financial engineering experts.

Finally, the trading strategy offers insight in the behavior of the stock market; it does not appear suitable for small investors to implement. Individual case of stock investment requires similar procedure of measuring relative performance of technical trading rules referred directly to potential investment opportunities.

\section{References}

Ben-Zion, U., Klein, P., Shachmurove, Y., \& Yagil, J. (2003). Efficiency Difference between the S\&P 500 and Tel-Aviv 25 Indices: A Moving Average Comparison. International Journal of Business, 8(3), 267-284. doi:10.2139/ssrn.420243.

Beogradska berza. (2014). Retrieved June 16, 2014, from http://www.belex.rs/trgovanje/ indeksi/belex15/istorijski.

Berkowitz, J., \& Kilian, L. (2000). Recent Developments in Bootstrapping Time Series. Econometric Review, 19(1), 1-48. doi:10.1080/07474930008800457.

Bessembinder, H., \& Chan, K. (1995). The Profitability of the Technical Trading Rules in the Asian Stock Markets. Pacific-Basin Finance Journal, 3(2), 257-284. doi:10.1016/0927538X(95)00002-3.

Brock, W., Lakonishok, J., \& LeBaron, B. (1992). Simple Technical Trading Rules and the Stochastic Properties of Stock Returns. Journal of Finance, 47(5), 1731-1764. doi:10.1111/j.1540-6261.1992.tb04681.x.

Chang, E., Lima, E., \& Tabak, B. (2004). Testing for Predictability in Emerging Equity Markets. Emerging Market Review, 5(3), 295-316. doi:10.1016/j.ememar.2004.03.005.

Charoenwong, B. (2012). An Exploration of Simple Optimized Technical Trading Strategies. Retrieved January 15, 2014, from http://deepblue.lib.umich.edu/bitstream/ handle/2027.42/91813/chben. pdf? sequence=1.

Chen, C. W., Huang, C. S., \& Lai, H. W. (2009). The Impact of Data Snooping on the Testing of Technical Analysis: An Empirical Study of Asian Stock Markets. Journal of Asian Economics, 20(5), 580-591. doi:10.1016/j.asieco.2009.07.008.

Coe, T., \& Laosethakul, K. (2010). Should Individual Investors Use Technical Trading Rules to Attempt to Beat the Market? 
American Journal of Economics and Business Administration, 2(3), 201-209. doi:10.3844/ ajebasp.2010.201.209.

Efron, B. (1979). Bootstrap Methods:Another Look at the Jackknife. Annals of Statistics, 7(1), 1-26. doi:10.1214/aos/1176344552.

Festić, M., Kavkler, A., \& Dajčman, S. (2012). Long Memory in the Croatian and Hungarian Stock Market Returns. Zbornik radova Ekonomskog fakulteta u Rijeci, 30(1), 115-139.

Fifield, S., Power, D., \& Sinclair, D. (2005). An Analysis of Trading Strategies in Eleven European Stock Markets. The European Journal of Finance, 11(6), 531-548. doi:10.1080 /1351847042000304099.

Garza-Gomez, X., \& Metghalchi, M. (2011). The Effects of Financial Modernization on Market Efficiency: the Case of Mexican Stock Market. Investment Management and Financial Innovations, 8(3), 89-101. doi:10.21511/imfi.14(1-1).

Gencay, R. (1998). Optimization of Technical Trading Strategies and the Profitability in Security Markets. Economic Letters, 59(2), 249-254. doi:10.1016/S0165-1765(98)00051-2.

Gunasekarage, A., \& Power, D. (2001). The Profitability of Moving Average Trading Rules in South Asian Stock Markets. Emerging Market Review, 2(1), 17-33. doi:10.1016/S15660141(00)00017-0.

Hansen, P., \& Lunde, A. (2005). A Forecast Comparison of Volatility Models: Does Anything Beat a GARCH $(1,1)$ ? Journal of Applied Econometrics, 20(7), 873-889. doi:10.1002/jae.800.

Kizys, R., \& Pierdzioch, C. (2011). The Financial Crisis and the Stock Markets of the CEE Countries. Finance a úverr-Czech Journal of Economics and Finance, 61(1), 153-172.

Kwon, K., \& Kish, R. (2002). Technical Trading Strategies and Return Predictability: NYSE. Applied Financial Economics, 12(9), 639-653. doi:10.1080/09603100010016139.

Kunsch, H. (1989). The Jackknife and the Bootstrap for General Stationary Observations. Annals of Statistics, 17(3), 1217-1241. doi:10.1214/aos/1176347265.

LeBaron, B. (1999). Technical Trading Rule Profitability and Foreign Exchange Intervention. Journal of International Economics, 49(1), 125143. doi:10.3386/w5505.

Lento, C. (2010). The Combined Signal Approach to Technical Analysis: A Review \& Commentary. Applied Economic Letters, 16(7), 749-753. doi:10.2139/ssrn.1410899.
Liu, R., \& Singh, K. (1992). Moving Blocks Jackknife and Bootstrap Capture Weak Dependance. New York: John Wiley \& Sons.

Ljubljanska borza. (2014). Market data. Retrieved June 16, 2014, from http://www.ljse. si/cgi-bin/jve.cgi?doc=2069.

Lonnbark, C., \& Soultanaeva, A. (2009). Profitability of the Technical Trading Rules on the Baltic Stock Markets. [Umea Economic Studies, Working Paper 761]. Retrieved January 15, 2015, from http://www.usbe.umu. se/digitalAssets/7/7765_ues761.pdf.

Macedonian Stock̄ Exchange. (2014). Retrieved June 16, 2014, from http://www.mse. mk/en/indicies/MBI10/values/100.

Marshall, B., Qian, S., Young, M., Chuang. S., \& Gielen, U. (2009). Is Technical Analysis Profitable on US Stocks with Certain Size, Liquidity or Industry Characteristics? Applied Financial Economics, 19(15), 1213-1221. doi:10.2139/ssrn.929954.

McKenzie, M. (2007). Technical Trading Rules in Emerging Markets and the 1997 Asian Currency Crises. Emerging Markets Finance and Trade, 43(4), 46-73. doi:10.2753/ REE1540-496X430403.

Metghalchi, M., Glasure, Y., Garza-Gomes, X., \& Chen, C. (2007). Profitable Technical Trading Rules for the Austrian Stock Markets. International Business \& Economics Research Journal, 6(9), 49-58. doi:10.19030/iber. v6i9.3405.

Metghalchi, M., Chang, Y., \& Marcucci, Y. (2008). Is the Swedish Stock Market Efficient? Evidence from some Simple Trading Rules. International Review of Financial Analysis, 17(3), 475-490. doi:10.1016/j.irfa.2007.05.001.

Mills, T. (1997). Technical Analysis and the London Stock Exchange: Testing Trading Rules Using the FT30. International Journal of Finance and Economics, 2(1), 319-331. doi:10.1002/ (SICl)1099-1158(199710)2:43.3.CO;2-Y.

Mitra, S. (2011). Usefulness of MovingAverage Based Trading Rules in India. International Journal of Business and Management, 6(7), 199206. doi:10.5539/ijbm.v6n7p199.

Montenegro berza. (2014). MONEX. Retrieved June 16, 2014, from http://www. montenegroberza.com/code/navigate. asp? $\mathrm{ld}=83$.

Papathanasiou, S., \& Samitas, A. (2010). Profits from Technical Trading Rules: the Case of Cyprus Stock Exchange. Journal of Money, Investment and Banking, 13(1), 35-43. doi:10.1080/00036846.2015.1013609. 
Parisi, F., \& Vasquez, A. (2000). Simple Technical Trading Rules of Stock Returns: Evidence from 1987-1998 in Chile. Emerging Market Review, 1(2), 152-164. doi:10.1016/ s1566-0141(00)00006-6.

Park, C. H., \& Irwin, S. (2007). What Do We Know About the Profitability of Technical Analysis. Journal of Economic Surveys, 21(4), 786-826. doi:10.1111/j.1467-6419.2007.00519.x.

Pauwels, S., Inghelbrecht, K., Heyman, D., \& Marius, P. (2012). Technical Trading Rules in Emerging Stock Markets. World Academy of Science, Engineering and Technology, 59(1), 2241-2264. doi:10.2139/ssrn.1998036.

Qi, M., \& Wu, Y. (2006). Technical TradingRule Profitability, Data Snooping and Reality Check: Evidence from the Foreign Exchange Market. Journal of Money, Credit and Banking, 38(8), 2135-2158. doi:10.1353/mcb.2007.0006.

Ratner, M., \& Leal, R. (1999). Test of Technical Trading Strategies in the Emerging Equity Markets of Latin America and Asia. Journal of Banking \& Finance, 23(12), 18871905. doi:10.1016/S0378-4266(99)00042-4.

Ready, M. (2002). Profits from Technical Trading Rules. Financial Management, 31(3), 43-61. doi:10.2139/ssrn.64168.

Ruiz, E., \& Pascual, L. (2002). Bootstrapping Financial Time Series. Journal of Economic Surveys, 16(3), 271-300. doi:10.1111/14676419.00170/pdf.

Stavarek, D., \& Heryan, T. (2012). Day of the Week Effect in Central European Stock Markets. E\&M Ekonomie a Management, 15(4), 134-146.

Sullivan, R., Timmermann, A., \& White, H. (1999). Data Snooping, Technical Trading Rule
Performance, and the Bootstrap. Journal of Finance, 54(5), 1647-1691. doi:10.1111/00221082.00163.

White, H. (2000). A Reality Check for Data Snooping. Econometrica, 68(5), 1097-1126. doi:10.1111/1468-0262.00152.

Wong, W., Manzur, M., \& Chew, B. (2003). How Rewarding is Technical Analysis? Evidence from Singapore Stock Market. Applied Financial Economics, 13(7), 543-551. doi:10.1080/09603 10022000020906.

Zagrebačka burza. (2014). Indeks CROBEX. Retrieved June 16, 2014, from http://www.zse. hr/default.aspx?id=44101\&index=CROBEX.

Žiković, S. (2008). Quantifying Extreme Risk in Stock Markets: A Study of Former Yugoslavia States. Zbornik radova Ekonomskog fakulteta u Rijeci, 26(1), 41-68.

Žiković, S., \& Aktan, B. (2009). Global Financial Crisis and VaR Performance in Emerging Markets: A Case of EU Candidate States - Turkey and Croatia. Zbornik radova Ekonomskog fakulteta u Rijeci, 27(1), 149-170.

Boris Radovanov, Ph.D. University of Novi Sad Faculty of Economics Subotica Department of Business Informatics and Quantitative Methods radovanovb@ef.uns.ac.rs

Aleksandra Marcikić, Ph.D. University of Novi Sad

Faculty of Economics Subotica Department of Business Informatics and Quantitative Methods amarcikic@ef.uns.ac.rs 


\section{Abstract}

\section{BOOTSTRAP TESTING OF TRADING STRATEGIES IN EMERGING BALKAN STOCK MARKETS}

\section{Boris Radovanov, Aleksandra Marcikić}

Most lately, the attention of technical trading analysis has shifted to emerging stock markets which collectively bring a significant alternative source of opportunities to international investors. Accordingly, the aim of this paper is to investigate the effectiveness of four technical trading rules (moving average, filter, trading range breakout and channel breakout rule) in six stock market indices of the Balkan States. Also, the paper is providing resume evidence on the predictive power of four mentioned trading rules. We apply the Reality Check and the Superior Predictive Ability test using bootstrap methodology to evaluate the relative performance of those rules. Furthermore, presented tests provide an answer to data snooping problems, which is essential to obtain unbiased outcomes. The original time series is resampled with random draw in two ways: a parametric residual-based method from the $A R(1)-G A R C H(1,1)$ model, and a nonparametric, the moving block bootstrap. After including data snooping biases, this study finds that the null hypothesis that trading rules do not outperform the benchmark can be rejected at the 5 percent significance level for five separate stock indices, excluding the MBI10 index. Similarly, such results show the rejection of the weak-form market efficiency hypothesis in case of mentioned stock markets. Applied technical trading rule algorithms in all six stock market indices mainly generate more losing trades then wining trades. Finally, transaction costs have relatively small effect on the overall performance of selected technical trading rules in case of indices BELEX15, CROBEX, SBITOP and MONEX20, but with some changes in choice of the best technical trading rule considering the effects of trading frequencies.

Key Words: Technical trading rules, stock market indices, market efficiency, bootstrap, data snooping.

JEL Classification: C15, C22, G14, G15.

DOI: 10.15240/tul/001/2017-4-008 